\title{
PROBLEMAS DE AGENCIA Y BÚSQUEDA DE RENTAS EN EL PROGRAMA DE PAGO POR SERVICIOS AMBIENTALES HIDROLÓGICOS DE MÉXICO
}

\author{
AGENCY PROBLEMS AND RENT-SEEKING IN THE PROGRAM OF \\ HYDROLOGICAL ENVIRONMENTAL SERVICES IN MEXICO
}

\author{
\begin{tabular}{l|l} 
Edgar Rivero Cob & $\begin{array}{l}\text { Insituto Nacional de Ecología } \\
\text { eriverocob@yahoo.com.mx }\end{array}$
\end{tabular}
}

\section{RESUMEN}

Se utiliza un modelo modificado de Von Thünen de cambio de uso de suelo para analizar cómo los grupos de interés y buscadores de rentas pueden influir en el diseño e instrumentación del Programa de Pago por Servicios Ambientales Hidrológicos de México (PSAH) a través de la provisión de información estratégica al regulador desvirtuando su objetivo de proveer incentivos económicos para evitar la deforestación en áreas donde existan serios problemas relacionados con el agua pero donde la actividad forestal no es competitiva con la agricultura y la ganadería. Se argumenta que la inversión en actividades de cabildeo y apropiación de rentas en la fase de diseño está en función de las rentas esperadas que obtendrían los grupos de interés. Si éstas están "aseguradas" ellos buscarán invertir en la fase de diseño; pero si no lo están, lo harán en la fase de instrumentación del PSAH pudiendo esto dar origen a que existan rentas sustanciales desperdiciadas por la sociedad en actividades no productivas. Siendo éste un problema clásico de agente -principal aplicado al mercado de servicios ambientales se sugiere que el establecimiento de mecanismos que alineen los incentivos 
entre el regulador y los grupos de interés llevaría al cumplimiento de los objetivos del PSAH con criterios de eficiencia económica.

Clasificación JEL: D72, D82, H41, H61, P48, Q28

Palabras clave: grupos de interés, buscadores de rentas, información asimétrica, política pública, proceso presupuestario.

\section{ABSTRACT}

It uses a modified Von Thünen's model of land use change to analyze how and why interest groups and rent seekers can influence the design and implementation of the Payment for Hydrological Environmental Services in Mexico (PWS) providing strategic information to the regulator undermining their goal of providing economic incentives to prevent deforestation in areas where there are serious problems with water but where forestry is not competitive with agriculture and livestock. It is argued that investment in lobbying and rent appropriation in the design phase is a function of expected income accruing to the stakeholders. If they are "insured" they seek to invest in the design phase, but if not, they will in the implementation phase of PSAH thus increasing income wasted by society in unproductive activities. As a classic problem of principal-agent theory applied to an environmental services market it follows the recommendation of the establishment of mechanism that align regulator's objectives with interest groups and rent seekers ones in order to meet PWS' objective with economic efficiency criteria.

Keywords: interest groups, rent seekers, asymmetric information, public policy, budget process 


\section{INTRODUCCIÓN}

La influencia de los grupos de interés y buscadores de rentas (rentseekers) en las decisiones públicas en un régimen democrático puede ser explicada a través de la teoría de la elección pública, economía política y del agente-principal analizando la interacción estratégica de los participantes en la creación y distribución de un presupuesto fijo. Si bien ha habido desarrollos teóricos muy vastos en ese campo del conocimiento, se ha limitado su aplicación empírica en países en desarrollo que requieren utilizar sus recursos privados y públicos escasos de manera eficiente, efectiva y equitativa.

Por lo anterior, se utiliza un modelo modificado de Von Thünen de cambio de uso de suelo para analizar cómo los grupos de interés y buscadores de rentas pueden influir en el diseño e instrumentación del Programa de Pago por Servicios Ambientales Hidrológicos de México (PSAH) a través de la provisión de información estratégica al regulador desvirtuando su objetivo de proveer incentivos económicos para evitar la deforestación en áreas donde existan serios problemas relacionados con el agua pero donde la actividad forestal no es competitiva con la agricultura y la ganadería. Se argumenta que la inversión en actividades de cabildeo y apropiación de rentas en la fase de diseño está en función de las rentas esperadas que obtendrían los grupos de interés. Si éstas están "aseguradas" ellos buscarán invertir en la fase de diseño; pero si no lo están, lo harán en la fase de instrumentación del PSAH pudiendo esto dar origen a que existan rentas sustanciales desperdiciadas por la sociedad en actividades no productivas. Siendo éste un problema clásico de agente -principal aplicado al mercado de servicios ambientales se sugiere que el establecimiento de mecanismos que alineen los incentivos entre el regulador y los grupos de interés llevaría al cumplimiento de los objetivos del PSAH con criterios de eficiencia económica.

El documento constará de los siguientes apartados: 1) Antecedentes, en los que se describe la influencia de los grupos de presión para la creación del PSAH en un régimen político democrático; 2) Revisión de a literatura de los grupos de interés, búsqueda de rentas, agente principal y 
su conexión con la creación y distribución de un presupuesto fijo; 3) Aplicación de la teoría revisada en el caso del diseño e instrumentación del PSAH utilizando el modelo modificado de Von Thünen y 4) Reflexiones de políticas públicas para mejorar la eficiencia, efectividad y equidad del PSAH.

\section{ANTECEDENTES}

Uno de los más grandes avances en la democracia mexicana de los últimos diez años ha sido la mayor transparencia y la participación ciudadana en la toma de decisiones públicas. Dichos avances se ven reflejados desde el Congreso de la Unión en donde se discuten y aprueban diversas iniciativas legislativas y el presupuesto público federal ${ }^{1}$ orientado a financiar diversos programas y proyectos ${ }^{2}$ que se hacen en nombre del interés público. Por otro lado, el Poder Ejecutivo Federal ha instrumentado diversos mecanismos de consulta ciudadana ${ }^{3}$ para la elaboración del Plan Nacional de Desarrollo y sus programas sectoriales y especiales. A la fecha, en la Semarnat existe el Consejo consultivo nacional para el desarrollo

\footnotetext{
${ }^{1}$ Rivero (2008) analizó ¿cómo en un gobierno democrático dividido una modificación a las reglas de discusión y aprobación del presupuesto federal afecta los incentivos de los legisladores y los grupos de interés (a través de los legisladores) en la Cámara de Diputados para la generación de coaliciones entre grupos parlamentarios? El autor demostró que la modificación al artículo 74 constitucional en el que se le otorgaban mayores facultades en la discusión, aprobación y reasignación del presupuesto federal a los legisladores; se generaron incentivos para construir coaliciones entre diputados de mayoría relativa de diferentes grupos parlamentarios para conseguir mayores presupuestos a los estados a los que pertenecen, se incrementó de manera considerable el número de solicitudes de reasignación de partidas presupuestales hacia sus distritos electorales y el monto total de estas solicitudes pasó de ser $0.8 \%$ del gasto neto total programable del gobierno federal a $4.2 \%$ en los años antes mencionados.

${ }^{2}$ Red MOCAF A.C., 2009.

${ }^{3}$ En el mecanismo de consulta ciudadana instrumentada por la oficina de la Presidencia de la República para la elaboración del Plan Nacional de Desarrollo 2007 - 2012 participaron 131 mil 918 personas, entre foros de consulta popular, páginas de internet, centro de atención telefónica, correo postal y correo electrónico (disponible en http://pnd.presidencia.gob.mx/pdf/Resultados_de_la_Consulta_Ciudadana_para_el_PND.pdf)
} 
sustentable, que agrupa 91 integrantes, 42 representantes de los consejos regionales y 49 integrantes de los grupos principales (Comisión Nacional de Áreas Naturales Protegidas (CONANP), Congreso de la Unión, Perspectiva de género, Pueblos indios, Asociación de profesionistas, Organizaciones de jóvenes, Organizaciones sociales, ONGs, Instituciones de educación superior y Organizaciones empresariales e industriales, entre otros). En este marco de apertura democrática el programa Pago por servicios ambientales hidrológicos (PSAH) se originó, en buena medida, por la presión ejercida por diversas organizaciones sociales como el Consejo Nacional de Organizaciones Campesinas (CONOC), Red Mexicana de Organizaciones Campesinas Forestales (Red MOCAF), Coordinadora Nacional de Organizaciones Campesinas (CNOC), Asociación Nacional de Empresas Comercializadoras de Productores del Campo (ANEC), entre otras, mismas que firmaron con el Poder Ejecutivo Federal el Acuerdo Nacional para el Campo (Presidencia de la República de México, 2003), para exigir "la implementación, reconocimiento y pago de los servicios ambientales y de protección ante el cambio climático de la aportación de las comunidades campesinas en la conservación de áreas naturales protegidas y el mantenimiento y mejora de las superficies agroforestales". De las 20 reuniones que sostuvieron esas organizaciones con la Comisión Nacional Forestal, Conafor, durante 2003, derivadas del seguimiento del ANC, se lograron, entre otros, los siguientes compromisos: 1) "Se crearía un Comité Técnico para definir los criterios de calificación y la revisión y aprobación de las solicitudes" y 2) "Se definieron criterios de calificación, de las solicitudes como estar en áreas marginadas, población indígena, participación de mujeres, etc." (CEDRSSA, 2006). La creación del Comité también fue avalada y sugerida por el Banco Mundial. Desde su creación el PSAH contó con un comité técnico y un consejo consultivo. El comité técnico está conformado por funcionarios del gobierno federal y de la sociedad civil organizada para velar por el cumplimiento de los objetivos del PSAH. El Comité se reúne cada seis meses y sus acuerdos son llevados como recomendaciones ante el consejo consultivo quienes podrían o no tomarlos en cuenta. El Comité toma sus decisiones por mayoría de votos y se

${ }^{4}$ Cfr. Acuerdo Nacional para el campo, firmado el 28 de abril de 2003, numeral 198. 
levantan minutas de sus acuerdos, en él se presentan las propuestas de reformas a las reglas de operación del PSAH para el ejercicio fiscal siguiente y se discuten las modificaciones que se realizarían con miras a incrementar la eficiencia y efectividad del Programa. El Comité está integrado por al menos seis representantes de los siguientes sectores: a) proveedores de servicios ambientales, b) organizaciones civiles, c) usuarios de servicios ambientales, d) instituciones académicas y/o de investigación, e) organizaciones de profesionales y f) instituciones gubernamentales, mismos que cuentan con derecho a voz y voto, desde su creación ha sido presidido por representantes del Consejo mexicano para la silvicultura y del Fondo mexicano para la conservación de la naturaleza. El establecimiento del Comité es una iniciativa innovadora para que miembros de las organizaciones de la sociedad civil (OSC) participen en el diseño, y evaluación de políticas públicas ambientales. En este Comité, el Instituto Nacional de Ecología (INE) tiene la responsabilidad de proveer de información con evidencia científica para una participación pública informada y responsable en la toma de decisiones.

\section{REVISIÓN DE LA LITERATURA}

\section{1. ¿Cómo influyen los grupos de interés en las políticas públicas ambientales en una democracia?}

La influencia de los grupos de interés y buscadores de rentas (rentseekers) en las decisiones públicas en un régimen democrático puede ser explicada a través de la teoría de la elección pública y la economía política.

La teoría de la elección pública basa su análisis en dos supuestos principales sobre el comportamiento de los miembros de una colectividad: 1) a pesar de que los individuos aprecian el potencial de una economía de mercado para generar riqueza produciendo, consumiendo y distribuyendo bienes privados, quieren también la provisión de bienes públicos, 2) ellos creen que pueden beneficiarse al hacer un acuerdo colectivo para que alguien provea en su representación esos bienes públicos. Durante la elaboración del acuerdo se dan cuenta de que enfrentan altos costos de tomar 
decisiones colectivas, para evitarlos o reducirlos acuerdan una regla de votación y un sistema de elección de sus representantes para la elaboración de leyes y regulaciones en su beneficio.

Esta combinación de situaciones, da a la gente incentivos para buscar influir en los legisladores y reguladores ya sea para corregir una falla de mercado para promover leyes y decisiones administrativas en su propio beneficio y en perjuicio de otros miembros de la colectividad. Así las cosas, la búsqueda de rentas (rent-seeking) se refiere a las leyes o decisiones administrativas creadas a partir de la influencia de grupos de interés que son desperdiciadoras de recursos de la economía en términos netos.

En un sistema donde ya están dadas las condiciones de mercado existen dos tipos de búsqueda de rentas: 1) privilegios de mercado, es decir, se garantizan privilegios a ciertas personas que participan en el mercado y se excluye a otras de los mismos, por lo que al interferir en la libre competencia se reduce la capacidad de la economía de generar riqueza y disminuye la eficiencia económica, 2) la redistribución de rentas, que aunque no afecta la libertad de competencia, si influye en los incentivos para la generación de riqueza pues se desvían recursos de usos productivos a aquellos que no lo son.

\subsection{El modelo básico de búsqueda de rentas}

El modelo más simple de búsqueda de rentas especifica que cualquier renta artificialmente creada, ${ }^{5}$ podría ser disputada por los agentes que buscan tener parte de esas rentas (Flowers, 1987). En la competencia por estas rentas los agentes utilizarían recursos reales de la economía (rectángulo $\mathrm{C}$ de la gráfica 1), que tendrían que ser sumadas a la pérdida neta de bienestar que genera una falla de gobierno en los mercados competitivos (aranceles, subsidios, impuestos, etc.) (triángulo H). En el modelo competitivo de búsqueda de rentas, todas las rentas potenciales son disipadas (Tullock, 2003). Una implicación relevante de este modelo simple es que nadie gana de una intervención inadecuada del gobierno en un mercado competitivo.

\footnotetext{
${ }^{5}$ Cualquier "exceso" de renta que esté por encima del costo de oportunidad de un propietario de recurso (Tollison, 1982".
} 
Browning (1974, citado por Flowers, 1987) hace una diferencia entre la creación y la distribución de una renta. La aprobación de una legislación que hace posible la emergencia de una renta en un mercado particular es un tipo de bien de consumo colectivo, ya que múltiples agentes tienen acceso potencial en la repartición de la renta. Si seguimos el argumento el problema del free-rider (gorrón) disminuirá los incentivos de los agentes a invertir en cabildeo y otras actividades para conseguir el beneficio de la falla del gobierno. Sin embargo, una vez creada la renta, es divisible, lo cual sugiere que el desperdicio social asociado con la búsqueda de rentas es, probablemente mayor durante la fase de distribución.

Otra consideración que también requiere atención es que la disposición a invertir de los beneficiarios potenciales en actividades de búsqueda de rentas durante la fase de la creación, a diferencia de la fase de distribución, depende del valor esperado de las rentas que obtendrían una vez que ésta ya fue creada. Si la asignación final es "asegurada" es más probable que los buscadores de rentas inviertan recursos importantes durante la fase de creación, que durante la fase de asignación.

Gráfica 1 Modelo básico de la búsqueda de rentas

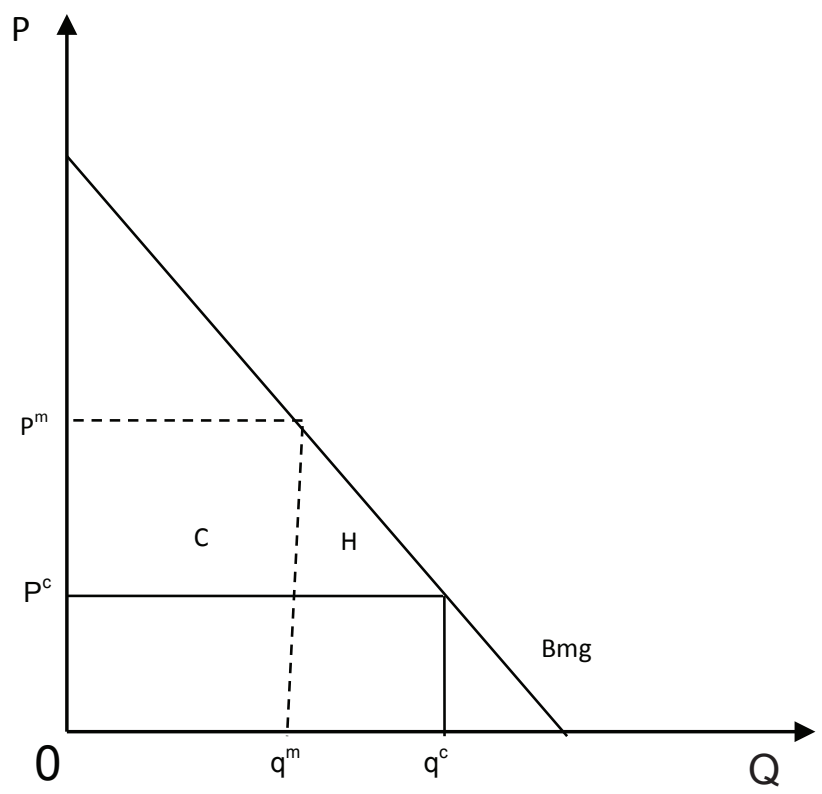


De acuerdo con el modelo básico de búsqueda de rentas antes señalado, éstas son disipadas debido a que no existen barreras a la entrada y los grupos de interés se disputan las rentas fijas totales que fueron creadas a través de alguna decisión y falla del gobierno. Sin embargo, diversos análisis han concluido que no sólo a través del lado de la demanda se podrían disipar las rentas totales, sino también por el lado de la oferta. Una forma de visualizar esto, es si los políticos y burócratas (los oferentes de tales rentas) son capaces de "extraer" la máxima disposición a pagar de los demandantes de sus "servicios" exclusivos a través de una discriminación perfecta de precios, para capturar todo el excedente de los consumidores de servicios políticos. La teoría de la competencia de los oferentes de rentas es más entendible si se parte del supuesto de que existe un grupo de representantes electos (i.e. legisladores, funcionarios) que tienen incentivos para competir entre ellos - al buscar la reelección o la permanencia en sus posiciones de decisión - mediante los precios y pagos que esperan recibir de una legislación o regulación favorable a los que demandan sus servicios. No obstante, en este modelo, no todos los demandantes de rentas pueden salir beneficiados, ya que solamente se requieren los votos de la mayoría simple de los potenciales beneficiados para ganar la elección. Si los compradores potenciales de una regulación favorable del gobierno tienen éxito al organizarse en una unidad colectiva (sindicatos, asociaciones o algún grupo similar) ellos tendrían ventaja en la negociación respecto a otros vendedores de votos (Flowers, 1987).

\subsection{Problemas de agencia y búsqueda de rentas en el proceso presupuestario}

La teoría de la elección pública y del agente-principal es también útil para analizar el proceso político de la toma de decisiones respecto a la distribución de un presupuesto fijo, enfocándose en las interacciones entre dos participantes: 1) el principal, es decir, el público en general (los representados) y 2) los agentes (los representantes/tomadores de decisiones), estos últimos caen en dos categorías, los funcionarios electos (el Presidente y los legisladores) y los empleados (burócratas) de los departamentos administrativos (ver figura 1). Aun entre los representantes existe también 
una jerarquía: el Presidente (el agente) con el aval del Congreso (el principal) delega a los funcionarios que ejecuten el mandato legislativo, quienes, a su vez, ordenan su instrumentación administrativa a los burócratas de diferentes departamentos. En otro nivel de análisis, el Presidente puede convertirse en el principal y los funcionarios y burócratas en agentes, y así sucesivamente. Sin embargo, no hay que perder de vista que el principal de mayor jerarquía es el público en general, en otras palabras, los electores, votantes, los contribuyentes o "la sociedad", quienes delegan en otros tomar las decisiones por ellos.

En la teoría clásica del agente - principal, una parte (el principal) le deja a otra (el agente) algunos derechos de decisión para realizar transacciones en un mercado, debido a que el agente tiene mayores habilidades, recursos o información para llevar a cabo las tareas encomendadas por aquél. No obstante, existen ciertos conflictos de interés en esta relación, ya que el principal es incapaz de monitorear las actividades perfectamente y recibir la misma información que posee el agente sin incurrir en algún costo. Luego entonces, los problemas de agencia se deben a la información asimétrica. El principal quiere que el agente actúe en su propio interés, pero los intereses del agente pueden ir en otra dirección.

Este asunto de divergencia en los intereses y metas es la esencia del argumento de la teoría del agente-principal. La teoría de la agencia asume que los agentes no transmiten adecuadamente la información al principal referente a sus habilidades, conocimiento y esfuerzo. La alternativas existentes para el principal para tratar estos problemas son la alineación de incentivos y el monitoreo. En el primer caso, los incentivos se establecen de tal forma que al tratar el agente de maximizar sus propios incentivos también maximiza los incentivos del principal. En el segundo caso, el monitoreo se refiere a cualquier acción dirigida a proveer al principal con información referente al comportamiento del agente.

\footnotetext{
${ }^{6}$ En el caso de la provisión de bienes y servicios públicos, la sociedad puede decidir no organizarse, ni tratar de influir en la toma de decisiones, por problemas de acción colectiva e ignorancia racional. Ya que pueden obtener los beneficios potenciales que proveería el bien o servicio público suministrado por el gobierno, sin incurrir en los costos de su provisión, al dejar que otros lo hagan por ellos o porque los costos marginales en los que incurrirían son superiores al beneficio marginal de hacerlo.
} 
Figura 1 Un enfoque de agente-principal en el proceso presupuestario y rendición de cuentas en México
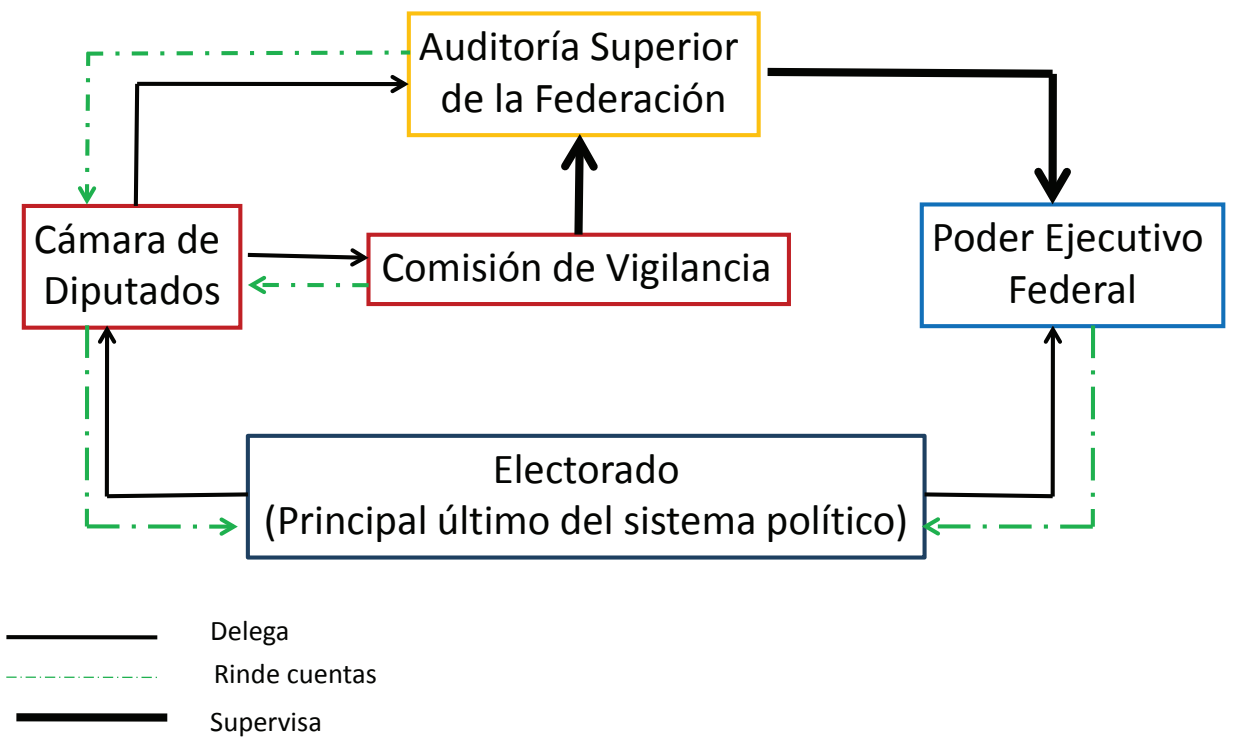

Fuente: Elaboración propia con base en Ugalde (2002).

El electorado como último principal delega en el Poder Legislativo la función de elaborar leyes, distribuir el presupuesto y controlar, a través de la Auditoría Superior de la Federación, ASF), el ejercicio del gasto público y el alcance de metas y objetivos del Poder Ejecutivo Federal. A su vez, la Cámara de Diputados se auxilia de la Comisión de vigilancia para supervisar los trabajos de la ASF. El Poder Ejecutivo Federal, por su parte, se vale de la Secretaría de la Función Pública y de las contralorías internas en cada dependencia, entidad y organismo, para analizar el uso transparente de los recursos públicos. Finalmente, el Poder Ejecutivo Federal, mediante las reglas de operación y lineamientos de sus programas y proyectos, puede incluir a los ciudadanos organizados y no organizados en la toma de decisiones sobre el uso adecuado de los recursos públicos, a través de los consejos, comisiones, comités y grupos de trabajo, como, por ejemplo, el comité técnico consultivo del PSAH (Ver Figura 1). 
Los institutos de investigación (Instituto Nacional de Ecología, INE, universidades, etc.) y los organismos de evaluación (Consejo Nacional de Evaluación de la Política de Desarrollo Social, Coneval) proveen de información tanto al agente como al principal para que los incentivos se alineen hacia un mismo objetivo: maximizar la riqueza de ambos dados los recursos escasos disponibles.

En una democracia las instituciones son las que definen el papel de los tomadores de decisiones, las responsabilidades, oportunidades e incentivos de los individuos y sus representantes. En México, el proceso presupuestario se divide en cuatro etapas: la formulación del presupuesto por el Ejecutivo, la revisión y aprobación por el Legislativo, la ejecución del gasto público y el control y auditoría del mismo. En cada una de las etapas se involucran diferentes agentes, cada uno de ellos con un papel asignado en las leyes. Así también, cabe señalar que este proceso no es lineal, ya que las etapas se enciman unas con otras en determinado ejercicio fiscal (Guerrero y López, 2000).

El proceso presupuestario puede visualizarse como una secuencia de decisiones que crea una gran "bolsa" de recursos de acceso común del cual se financian una gran variedad de programas, la transferencia de ingreso a los individuos y empresas, así como la provisión directa de bienes y servicios públicos (Brubaker, 1997).

De acuerdo con Brubaker (1997), el proceso presupuestario crea incentivos y consecuencias similares a aquellos asociados a la tragedia de los comunes, ya que esto ocurre cuando no existen derechos de propiedad bien definidos de un recurso no renovable lo que crea incentivos para que los usuarios potenciales lo exploten de una manera excesiva.

Al convertir recursos privados en recursos de acceso común, mediante el pago de impuestos al ingreso, tarifas, derechos, entre otros, el proceso presupuestario crea su propia tragedia (Brubaker, 1997). Si bien la teoría microeconómica sostiene que esos fondos comunes deben destinarse a la creación de bienes públicos, en la práctica esos recursos son objeto de apropiación de grupos de interés, que buscan asegurar una asignación de los mismos para beneficio propio. Como resultado, los fondos comunes muy a menudo no solamente financian bienes públicos sino que son divididos entre buscadores de rentas que compiten por ellos. 
La búsqueda de rentas es un concepto de la teoría de la elección pública muy útil en describir las consecuencias de la toma de decisiones como parte de los procesos presupuestarios establecidos en un contexto institucional dado. En términos generales, la búsqueda de rentas se refiere a la apropiación de ingresos o riqueza por medios legales, a través de actividades no productivas tales como la adquisición de poder de mercado, cabildeo por mayores subsidios, reglas favorables o el otorgamiento de licencias para la prestación de algún servicio público (Brubaker, 1997). La búsqueda de rentas incentiva la transferencia de actividades productivas hacia aquellas que son improductivas. Los individuos podrían encontrar más ventajoso vivir improductivamente, basados en el fondo común, que obtener ingresos directamente de actividades productivas. Ya que los buscadores de rentas viven a expensas de otros, tienen menores incentivos para ahorrar, invertir en la formación de capital humano o físico o ser emprendedores empresariales que corren riesgos.

Existen dos fuentes potenciales de decisiones que resultan en ineficiencia respecto al proceso presupuestario: 1) El diseño de los programas públicos se conforma con base en las preferencias aproximadas de los votantes, ya que pueden existir cambios periódicos en los representantes y a que el contacto entre éstos y los votantes es muy infrecuente. Los representantes sirven a ciudadanos muy heterogéneos, y la mayoría de los principales solamente pueden comunicar en agregado sus preferencias o a través de muestras a las que pertenecen. En ningún caso, los agentes comprenden los detalles de las preferencias de los principales, sobre todo, si los votos de los ciudadanos no reflejan la intensidad de una preferencia sino sólo su sentido, 2) Debido a que los grupos pequeños y bien organizados gozan de ventajas sobre aquellos que no lo están o son muy grandes, los primeros comunican en mejor medida a los funcionarios electos sus preferencias al enviar información de manera sesgada para obtener resultados a su favor. Por lo tanto, los grupos de presión encuentran muy valioso informar a sus miembros y a los legisladores y reguladores acerca de los temas de su interés con el objetivo de maximizar sus beneficios. Estos grupos organizados pueden ganar grandes rentas a expensas de los grupos más grandes de contribuyentes quienes, a primera vista, individualmente sólo sufren pequeñas pérdidas. 
En este sentido, Tullock (2003) observó que existe una alta probabilidad de que el tomador de decisiones evada sus responsabilidades o trabaje de manera óptima si invierte demasiado poco tiempo o esfuerzo en investigar y reunir información sobre el tema de la decisión pública o al pretender el tomador de decisiones utilizar sus propias preferencias más que las del público en general. Por estas razones Tullock (Op. Cit.) considera que las decisiones públicas no necesariamente promoverán el interés general. De hecho, un programa podría ser promovido en el nombre del interés público (como bien público), pero podría ser impulsado y utilizado por los grupos de interés para generar beneficios para ellos mismos y dañar al público en general (el principal) durante el proceso.

Es por ello que resulta fundamental analizar cuáles son los incentivos que enfrentan los participantes en la toma de decisiones para la generación de un bien público y comparar arreglos institucionales alternativos para determinar si a través de un cambio en los incentivos de los participantes se podrían obtener resultados superiores.

\section{ANÁLISIS DEL CASO PSAH: ESTRATEGIAS PARA DISMI- NUIR LA BÚSQUEDA DE RENTAS Y ALCANZAR RESULTA- DOS ÓPTIMOS}

El Programa de pago por servicios ambientales hidrológicos (PSAH) fue concebido como un instrumento que jugaría un papel clave en aquellas áreas de importancia hidrológica amenazadas por la deforestación inducida y donde otras políticas habían probado ser inefectivas (Muñoz et al., 2007). El PSAH tiene el objetivo de proveer incentivos económicos para evitar la deforestación en áreas donde existan serios problemas relacionados con el agua, pero donde la actividad forestal no es competitiva con la agricultura y la ganadería.

El PSAH consiste en pagos directos a los propietarios de tierras con cobertura forestal primaria (es decir, bosques en buen estado de conservación). Parte del esquema innovador del Programa es que está financiado a través de los ingresos fiscales que recauda el gobierno federal por concepto de pago de derechos y crea un vínculo entre aquellos que se benefician de los servicios ambientales y aquellos quienes los proveen. 
Desde sus orígenes se reconoció que el diseño del PSAH no podía basarse en el supuesto de un mercado competitivo ya que la mayoría de los servicios ecosistémicos relacionados con el los bosques son bienes públicos en una escala regional. En este sentido, el gobierno, ya sea federal, estatal o municipal, podría actuar como intermediario entre los propietarios de los bosques y los ciudadanos y empresas quienes se benefician de tener agua limpia y abundante o de la disminución de los impactos de los desastres naturales relacionados con el agua. Así las cosas, el Programa fue diseñado como un monopsonio en el cual el gobierno tiene el papel de único comprador, quien podría elegir los predios que serían pagados, el tipo de acciones que serían compensadas y el precio que se pagaría.

De alguna manera, el PSAH tiene su origen como una de las 283 acciones que surgen del Acuerdo nacional para el campo (ANC) firmado en abril de 2003 a raíz de la integración de las demandas de más de diez mil productores del campo y dos mil ponencias que se presentaron y recogieron en más de ocho mesas de diálogo por una "Política de Estado para el campo" (Aserca, 2003). Si bien ese ejercicio constituyó un paso fundamental para avanzar hacia una democracia efectiva (Plan Nacional de Desarrollo, pag. 38), el movimiento se originó para la incorporación de ideas frescas e innovadoras en el diseño de las políticas públicas rurales y reducir la brecha que separa a los ciudadanos de sus representantes como tomadores de decisiones en la asignación eficiente, efectiva, controlada, transparente y equitativa de los recursos públicos (Ley federal de presupuesto y responsabilidad hacendaria, LFPRH, artículo 1), también reafirma la hipótesis de Browning (1974) en el sentido de que la disposición a invertir de los grupos de interés en actividades no productivas (búsqueda de rentas) está en función del valor esperado de las rentas que se obtendrían una vez que ésta ya fuera creada. Lo anterior ya que, según se desprende de un análisis del Centro de Estudios para el Desarrollo Rural Sustentable y la Soberanía Alimentaria, CEDRSSA (2006: pag. 1): “en 2003, con las negociaciones del Acuerdo Nacional para el Campo, algunas organizaciones introdujeron que en las acciones de corto plazo se incluyera la asignación de 200 millones de pesos para un programa de pago por servicios ambientales y en los cuales también debería incluirse de 
manera específica el café". No obstante que las negociaciones para incluir el café como cultivo agroforestal susceptible de recibir el pago de servicios ambientales no fructificaron, la cifra que al final fue negociada entre los funcionarios de la Conafor, Secretaría de Hacienda y Crédito Público y el Congreso de la Unión (legisladores cercanos a las demandas de las organizaciones rurales) se aproximó al monto antes señalado.

Uno de los primeros pasos en el diseño del PSAH —además de demostrar científicamente la relación entre la conservación de los bosques y los servicios hidrológicos y actuar bajo el principio de precautoriedadfue la creación del mecanismo financiero que respaldara en términos del presupuesto público la operatividad del programa. El mecanismo fue establecido a través de la reforma al artículo 223 de la Ley federal de derechos (LFD) para establecer que

"de los ingresos que se obtengan por la recaudación de los derechos por la explotación, uso o aprovechamiento de aguas nacionales por usuarios distintos de los municipales y organismos operadores de los mismos 300 millones de pesos tendrían destino específico para el Fondo Forestal Mexicano para el desarrollo de Programas de Pago por Servicios Ambientales" (LFD: pag. 168).

Si bien la autorización de 300 millones de pesos con destino específico no genera por sí sola la creación de rentas que estén destinadas para determinados grupos de interés, si ofrecen un indicador de que la búsqueda de rentas (el desperdicio de recursos en actividades improductivas) se daría en la fase de distribución de esas rentas, sobre todo si hay libre acceso y competencia por esos recursos presupuestales escasos de acceso común (Brubaker, 1997). Esto también puede deberse a que en virtud de que las rentas potenciales no están "aseguradas" para ciertos grupos de interés (i.e. los productores de café), éstos tendrán incentivos a comportarse como free-riders, ya que dejarán que otros grupos carguen con los costos de las actividades de cabildeo para la generación de los fondos comunes y esperarán invertir en esas actividades durante la fase de distribución, ya que se vuelven rentas fijas, escasas y limitadas por las que existirá una feroz competencia (Flowers, 1987). 
Ahora bien, aún con una elevada participación de grupos de presión en la creación del fondo común de recursos presupuestales, durante la fase de distribución de las rentas puede presentarse el problema de la acción colectiva por el lado de la demanda de bienes públicos puros (no así por el lado de la oferta ya que los proveedores se disputarían la renta fija creada por la falla de gobierno), pues los usuarios de éstos podrían actuar racionalmente y no contribuir por la generación de ese bien ya que por la dificultad de la exclusión de su disfrute los que no revelen su verdadera disposición a pagar terminarían siendo beneficiados de todas formas sin necesidad de incurrir en algún costo privado (Poteete y Ostrom, 2002) . Esto traería como consecuencia que no sólo habría una recaudación menor para el pago de servicios ambientales sino que también se daría una provisión sub-optima de los mismos Lo anterior puede observarse en el resultado de la negociación de la reforma al artículo 223 de la Ley federal de derechos, donde quedaron excluidos del cobro de derechos para el Pago de servicios ambientales (PSA) los usuarios municipales y sus organismos operadores, aun y cuando ellos se beneficiarían de los pagos por acciones de conservación de los otros usos (agrícola, ambiental, consuntivo, acuacultura, industrial y pecuario). ${ }^{7}$

Si bien la teoría microeconómica sostiene que los recursos privados (salarios, rentas por la propiedad, intereses por ahorros y préstamos, etc.) que son convertidos a recursos públicos de acceso común (presupuesto público) mediante los impuestos, tarifas, cuotas y derechos deberían destinarse a la corrección de fallas de mercado como la provisión de bienes y servicios públicos en la práctica esos recursos podrían ser objeto de apropiación de grupos de interés que buscan asegurar una asignación por diversos medios (prebendas, pago de comisiones, envío de información que favorece sus intereses, etc.), para beneficio propio (Brubaker, 1997).

Recordando lo mencionado en secciones anteriores, existen varias fuentes potenciales por las que las decisiones públicas pueden ser ineficientes al momento de proveer un bien o servicio público, sin embargo, las dos más importantes son: 1) que los tomadores de decisiones - los agentesdiseñan los programas públicos con base en preferencias aproximadas de los

\footnotetext{
${ }^{7}$ Ley de aguas nacionales. artículo 3 . Se consideraron a los usos domésticos y público urbano como parte de los usuarios municipales y de los organismos operadores.
} 
votantes - el principal- (por el problema de la agregación de preferencias colectivas) o en sus propias preferencias (para ahorrarse el costo de investigar y reunir información adecuada sobre el tema de interés del electorado) y 2) por las ventajas que tienen los grupos organizados y con pocos miembros (que pueden superar los costos de transacción de ponerse de acuerdo internamente) de comunicar en mejor medida a los funcionarios electos - que buscan su reelección o la ratificación en sus puestos de decisión consiguiendo votos - sus preferencias, al enviar información de manera sesgada para obtener resultados a su favor.

En el caso del PSAH resulta más viable que los proveedores de los servicios ambientales superen los costos de organización y actúen como una unidad frente al regulador, pues ellos esperan obtener las rentas que se pudieran generar durante la etapa de distribución de los fondos comunes a expensas de los contribuyentes que, como usuarios de servicios ambientales, por problemas de acción colectiva no logran tener los incentivos suficientes para organizarse y participar en la toma de decisiones de distribución de los fondos, ya que, individualmente, solamente sufren pequeñas pérdidas de beneficios aunque sí incurren en un alto costo de informarse y participar.

Ciertamente el Comité técnico consultivo del PSAH se creó con el propósito de velar por el cumplimiento de los objetivos del programa al integrar a los actores más relevantes para el funcionamiento eficiente y efectivo del mismo. No obstante, en la práctica dicho Comité - como se demostrará conceptualmente más adelante- no sólo ha creado rentas a partir de los mecanismos de selección de predios y fijación de precios por las acciones de conservación de los bosques, sino que no ha sido la arena de resolución de conflictos a bajo costo que: i) diseñe las reglas para el discurso, debate y alcance de acuerdos entre los proveedores, usuarios, intermediarios y otros actores no organizados, ii) provea de información confiable y adecuada sobre el inventario y flujo de las unidades de los recursos, iii) envíe los incentivos adecuados para la participación de los usuarios de los servicios ambientales no organizados o iv) diseñe mecanismos que disminuyan los costos de transacción para su organización y participación como último principal (Ostrom, 2002). 
Una vez que se aprobó el presupuesto del Programa por la reforma a la Ley federal de derechos, fue necesario diseñar las instituciones o reglas que generarían los incentivos para el cumplimiento de los objetivos que el Programa estaría buscando alcanzar a través de la elaboración las reglas de operación, en las que se definen, entre otros: 1) ¿qué tipo de predios o bosques serían incluidos?, 2) ¿qué acciones serían recompensadas?, 3) ¿cuánto sería pagado? y 4) ¿qué mecanismos de cumplimiento de los contratos serían establecidos?

Si bien en las reglas de operación del programa Proárbol 2011 se define que el objetivo del PSAH es "conservar la cobertura boscosa, se logre la recarga de los acuíferos y manantiales y se evite la erosión de suelo" (Reglas de Operación de Proárbol, 2011: pag. 48), desde la perspectiva de la economía de los recursos naturales, el objetivo de políticas públicas es proporcionar a los pagadores de impuestos y derechos fiscales servicios ambientales de los bosques de alto valor en intercambio por sus contribuciones (Muñoz et al., 2007). Lo que significa que la focalización debe estar dirigida hacia aquellos bosques que son más importantes para el abasto de agua y que están en elevado riesgo de deforestación (bosques con altos costos de oportunidad de mantener los bosques por ser poco competitivas las actividades de conservación forestal frente a la agricultura o ganadería como principales amenazas al cambio de uso del suelo).

Si bien los cuatro puntos de decisión más importantes a considerar para la definición de las reglas de operación del programa son espacios propicios para la búsqueda de rentas en la etapa de distribución de las mismas, en este análisis se considera que es en la definición de los criterios de selección de los predios y el precio que se le pagará a los proveedores por las actividades de conservación donde existe una mayor probabilidad de que los grupos de interés definan los incentivos que generarían beneficios privados a su favor, y no en el interés del último principal - los usuarios de servicios ambientales contribuyentes por disposiciones de la LFD-.

La definición de los criterios para la selección de predios forestales susceptibles de pago recobró una gran importancia cuando la demanda de solicitudes de participación excedió la oferta de fondos disponibles 
para la operación del programa. El INE sugirió, desde entonces, que se incorporaran indicadores relacionados con el valor del servicio hidrológico que proveen los bosques con elevado riesgo de deforestación (elevados costos de oportunidad), como criterios primarios de evaluación de las solicitudes, y no sólo como prerrequisitos que los predios deberían cumplir para poder inscribirse al programa.

De acuerdo con Muñoz et al. (2011), una de las herramientas más importantes en el diseño de políticas públicas para aumentar la efectividad del programa de inscripción voluntaria son los criterios y reglas para su focalización. Lo anterior se logra a través de dos herramientas específicas: a) la elegibilidad para entrar al programa y b) la prelación para ser aceptado cuando hay más solicitantes que fondos.

La focalización pretende lograr el mejor resultado en relación con el objetivo último de las políticas públicas con un presupuesto dado. Para diseñar reglas sencillas que seleccionen el mejor conjunto de predios sólo se requeriría información del valor ambiental de diferentes bosques y la presión que enfrentan a ser deforestados. Sin embargo, como advierten (Engel et al. 2008, citados por Muñoz, et. al., 2011) el hecho de asignar pagos genera un espacio de presión política para la búsqueda de rentas a través de variar los criterios de asignación. El argumento de estos autores es que lo indirecto de los servicios ambientales, más aún cuando los programas son a escala nacional, los hace particularmente vulnerables a dicho fenómeno.

Con base en Muñoz et al. (Op. Cit.), el poder monopsónico del gobierno federal (como único comprador de los servicios ambientales en representación de los intereses del último principal) le permite elegir el precio con el que obtendrá los mayores beneficios netos y más si puede diferenciar entre grupos aplicándoles diversos precios. Como bien observan los autores, la facultad de determinar los precios es una de las herramientas más poderosas de la focalización, pues permite obtener distintas reacciones de los diferentes tipos de propietarios a los que se quiere influenciar. 
Figura 2. Discriminación de precios según riesgo de deforestación de los predios en el PSAH de México 2011.
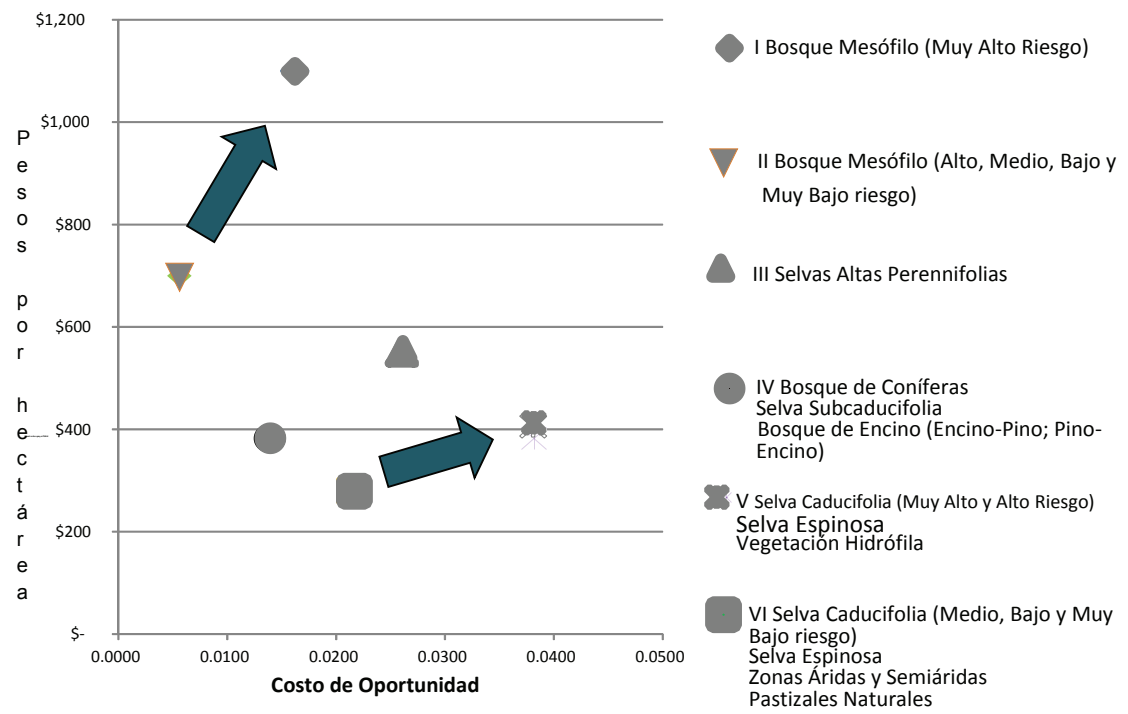

Fuente: Muñoz-Piña, Carlos, et. al., 2011 b/, “Análisis y recomendaciones de reforma a las Reglas de Operación de Proárbol-PSAH para el ejercicio fiscal 2012", Documento interno de trabajo del Instituto Nacional de Ecología.

La Figura 2 ilustra una discriminación de precios (pesos pagados por hectárea de bosque o selva conservada según el costo de oportunidad de cambiar el uso de suelo forestal a otro alternativo) sub-óptima, ya que si bien para dos ecosistemas (bosque mesófilo de montaña y selva caducifolia) se pagan mayores montos por hectárea conservada a mayor probabilidad promedio de que este tipo de predios sean deforestados (riesgo ó presión económica a la deforestación) esto no se aplica para otros ecosistemas como las selvas altas perennifolias, bosque de coníferas, selvas subcaducifolias y bosques de encino.

A pesar de su potencial, la diferenciación de precios ha sido muy poco utilizada en los programas nacionales de PSA. Esto puede deberse a que hay presiones políticas de los propietarios forestales para tener precios únicos o a que los funcionarios políticos buscan evitar críticas a la 
equidad del proceso $^{8}$ (Muñoz et al., 2007), en especial cuando la variable sobre la cual se quiere diferenciar los precios es algo no observable por los propietarios (que sí están representados —o sobrerepresentados— por sus organizaciones en los comités de toma de decisiones) como lo es el riesgo económico de la deforestación derivado de un modelo econométrico probabilístico (ver www.ine.gob.mx).

La evolución de las reglas de operación del PSAH en México a lo largo de los años reflejan un continuo conflicto entre búsqueda de rentas y eficiencia en las políticas públicas. Si bien focalizar a través de las zonas de elegibilidad tiene sentido desde el punto de vista de estrategia e instrumentación, sobre todo cuando los recursos son escasos, desde el principio los programas se enfrentan a una continua tensión entre limitar el área o ampliarla, tensión que viene del cabildeo: de las presiones internas y externas por canalizar recursos hacia zonas específicas (Muñoz et al., 2011). En la etapa del diseño y análisis del PSAH mexicano los tres servicios ambientales hidrológicos resaltados fueron: 1) protección de las áreas de recarga de los acuíferos, 2) protección de las cuencas donde había escasez de agua y 3 ) protección de áreas vulnerables a la inundación y otros desastres asociados a la precipitación extrema. Estos servicios fueron descritos en la Ley de desarrollo forestal sustentable y son la pieza más importante para definir elegibilidad. El problema de agregar zonas de elegibilidad adicionales es que cualquiera de las características relacionadas con dichas zonas son necesarias para conseguir la elegibilidad, y no todas en conjunto (Muñoz et al., Op. Cit.).

La focalización por prelación es necesaria cuando, dado un determinado pago ofrecido por hectárea, hay más solicitudes presentadas para participar en el programa por parte de propietarios forestales que fondos disponibles. La opción más utilizada es la de establecer un sistema de prelación de solicitudes, donde éstas se califican de acuerdo con un conjunto de criterios transparentes, con una métrica para ordenarlos según la prioridad y objetivos del programa respectivo (Muñoz et al., Op. Cit. ).

\footnotetext{
${ }^{8}$ El artículo 1 de la Ley federal de presupuesto y responsabilidad hacendaria (LFPRH) especifica que los sujetos obligados (dependencias, entidades, entes autónomos, entre otros) deberán observar que la administración de los recursos públicos federales se realice en base en criterios de honestidad, eficiencia, eficacia, economía, racionalidad, austeridad, transparencia, control, rendición de cuentas y equidad de género.
} 
El que los servicios ambientales sean de definición difusa y difícil medición deja un gran margen de maniobra para el gobierno que los compra. Se pueden incorporar diferentes predios y el valor ambiental de hacerlo sólo se conoce en el largo plazo. En 2006, a partir del trabajo conjunto del INE, Conafor y Banco Mundial que mostró serios problemas en la focalización del PSAH, se decidió introducir un sistema formal de prelación con los criterios objetivos de asignación mediante un sistema de puntos. Cuatro años de discusión técnica y el cabildeo externo e interno habían llevado a la inclusión de un número creciente de criterios a calificar dentro de las reglas de operación del PSAH. Se pasó de nueve criterios en 2006 a un total de 26 en 2010. El problema no resultó en el número de variables sino en el tipo y forma en que se habrían de combinar. En este caso se mezclaron, al mismo nivel, criterios primarios (hidrología, presión a la deforestación), criterios sociales (pobreza, género, etnicidad) y criterios secundarios (administrativos, participación en otros programas, entre otros), todos con pesos similares (Muñoz et al., Op. Cit.).

El problema no fue la inclusión de nuevos criterios, ya que en algunos casos fueron muy útiles, sino que el peso de los criterios secundarios ha crecido más que el de los primarios, estos últimos han bajado más consecuentemente, volviéndose irónicamente los predominantes y representar más de $2 / 3$ de la puntuación total. El bajo peso relativo de los criterios relacionados con los objetivos de política ambiental tiene sus consecuencias, ya que hay una gran cantidad de predios ambientalmente valiosos rechazados, mientras que predios de mucha menor importancia ambiental son aceptados (Muñoz et al., Op. Cit.).

Si establecemos como criterios centrales o primarios los relacionados con el evitar la deforestación en zonas que enfrentan problemas hidrológicos importantes, nos limitaríamos a los siguientes criterios de prelación ${ }^{9}$ : 1) Acuíferos sobreexplotados, 2) Disponibilidad de agua (escasez superficial) y parte funcional de la cuenca, 3) Índice de riesgo (presión económica) de deforestación, 4) Cobertura forestal, 5) Grado de degradación de suelos, 6) Riesgo de desastre natural y 7) Densidad de biomasa;

9 Según Muñoz, et al., 2011 b/ la mayor parte del país cubre con al menos un criterio primario por lo que aparentemente se cubre la equidad administrativa para participar en el programa. 
ninguno de ellos es calculado directamente por la Conafor como agente operador del programa lo cual podría garantizar parcialmente una mayor transparencia en el uso de los recursos públicos; sin embargo, las zonas (polígonos) de elegibilidad para el pago de PSAH sí son definidas por esta entidad pública.

En 2012 la Conafor había disminuido a 22 el número de variables a considerar para la calificación de solicitudes según pudo constatarse en las reglas de operación del Proárbol-PSAH para ese ejercicio fiscal. Bajo los supuestos anteriores, por primera ocasión en los últimos seis años, los criterios primarios representaron $51 \%$ del total de puntos máximos que podría obtener una solicitud que aspira a obtener un pago por $\mathrm{SAH}$, lo cual es un indicador de la rápida respuesta y capacidad de negociación del regulador frente a los grupos de presión representados en el Comité Técnico del PSAH ante la provisión de información científica que demostraba el desvío del programa de su objetivo central plasmado en el creciente peso relativo otorgado a los criterios no primarios al momento de seleccionar las solicitudes.

El esfuerzo de la Conafor por simplificar administrativamente el número de criterios de prelación hubiera sido más evidente si no se hubiera agregado ${ }^{10}$ la variable que otorgaba puntos extra a aquella solicitud que declarara su voluntad y obligación durante la vigencia del convenio de conservar entre $50 \%$ y $200 \%$ de la superficie adicional a la solicitada y pagada. Sin embargo, cabe señalar que este criterio sólo aplicaba a los predios en los que el criterio predominante sea selva. Este criterio parece poco práctico para los predios que tienen un elevado costo de oportunidad de cambiar el uso de suelo forestal a otras actividades económicas, sin embargo, podría ser atractivo (y ayudaría a revelar su información) para aquellos que tienen costos de oportunidad cero o negativos ya que éstos estarían dispuestos a conservar sin recibir nada o muy poco a cambio.

Al seguir los preceptos de la Ley federal de presupuesto y responsabilidad hacendaria la Conafor está obligada a ejercer su presupuesto a

\footnotetext{
${ }^{10}$ Esto debido que en las reglas de operación 2012 del Proárbol-PSAH se había eliminado el criterio "Solicitudes que estén dentro de los municipios de la estrategia 100 x 100" y el número total de variables hubiera disminuido a 21 respecto a los del año inmediato anterior.
} 
través de sus programas con los principios de eficiencia, eficacia, transparencia y equidad, el cual estará sujeto a la evaluación y control de los órganos correspondientes (LFPRH, art. 1 y 5).

Cabe señalar que desde 2010 el Consejo Nacional para la Evaluación de la Política de Desarrollo Social había advertido en sus reportes que "si bien la asignación de recursos cumple con las Reglas de Operación, los criterios de prelación no favorecen la focalización de recursos en zonas con mayor potencial de proveer SAH" (Coneval: 2011, pag. 17). Así también, este organismo evaluador recomendó que la Conafor realizara evaluaciones de los impactos del programa (i.e. deforestación que fue evitada como efecto directamente atribuible al programa), ya que solamente disponía de indicadores proxy o indicadores de resultados (i.e. porcentaje de la superficie forestal nacional que fue incorporada a un esquema de pago por servicios ambientales hidrológicos o superficie incorporada anualmente al PSAH), pero no de fines, y que, para este esfuerzo de análisis, podría apoyarse en el Instituto Nacional de Ecología.

Las recomendaciones del Coneval también fueron reforzadas por el CEDRSSA (órgano de investigación en el análisis de políticas públicas rurales al servicio del H. Congreso de la Unión), ya que, al revisar los indicadores de desempeño propuestos por la Semarnat por primera vez en el Proyecto de presupuesto de egresos de la federación (PPEF) 2008, se encontró que la mayoría de los indicadores no cumplían con las disposiciones normativas emitidas, ${ }^{11}$ los indicadores incluidos en el PPEF 2008 debieron ajustarse posteriormente ya que no estaban alineados a los programas sectoriales y especiales del sector ambiental (no se habían publicado en ese entonces). Dos de cada diez indicadores no disponían de una línea base y se recomendaba que las evaluaciones externas de impacto y resultados proveyeran los insumos necesarios para modificar los indicadores de seguimiento y evaluación del programa. Los indicadores de evaluación del desempeño que recomendó mejorar el Coneval en 2010 para tener estadísticas robustas de los resultados e impacto del programa son, en esencia, los mismos que el Congreso de la Unión observó como inadecuados, dadas las disposiciones normativas y metodologías aprobadas en 2008.

\footnotetext{
${ }^{11}$ Por ejemplo, los Lineamientos generales para la evaluación de los programas federales de la administración pública federal, entre otros.
} 
Es por esa razón, además de que fue algo detectado en 2006 derivado de los trabajos conjuntos de Conafor, Banco Mundial e INE, que se consideró necesario realizar un análisis de la focalización del programa $\mathrm{y}$, como resultado de ello, proponer recomendaciones de mejora para alcanzar las metas del programa (efectividad) con el presupuesto disponible (eficiencia) en el seno del Comité (transparencia) para que los proveedores fueran seleccionados bajo los mismos criterios (equidad), al seguir las recomendaciones de los órganos de evaluación (control) que en nombre del principal quieren maximizar sus beneficios netos, dado los recursos presupuestales escasos.

Para analizar cuáles son los indicadores de desempeño que ayudarían a focalizar mejor el PSAH nos auxiliaremos de la gráfica 2, que representa el modelo básico de Von Thûnen modificado, en el que se puede observar en el eje horizontal la distancia al mercado de los predios forestales y en el eje vertical el costo de oportunidad del uso del suelo (en pesos por hectárea).

Gráfica 2. Modelo básico de Von Thunen modificado para incorporar criterios de eficiencia, eficacia y equidad en el PSAH

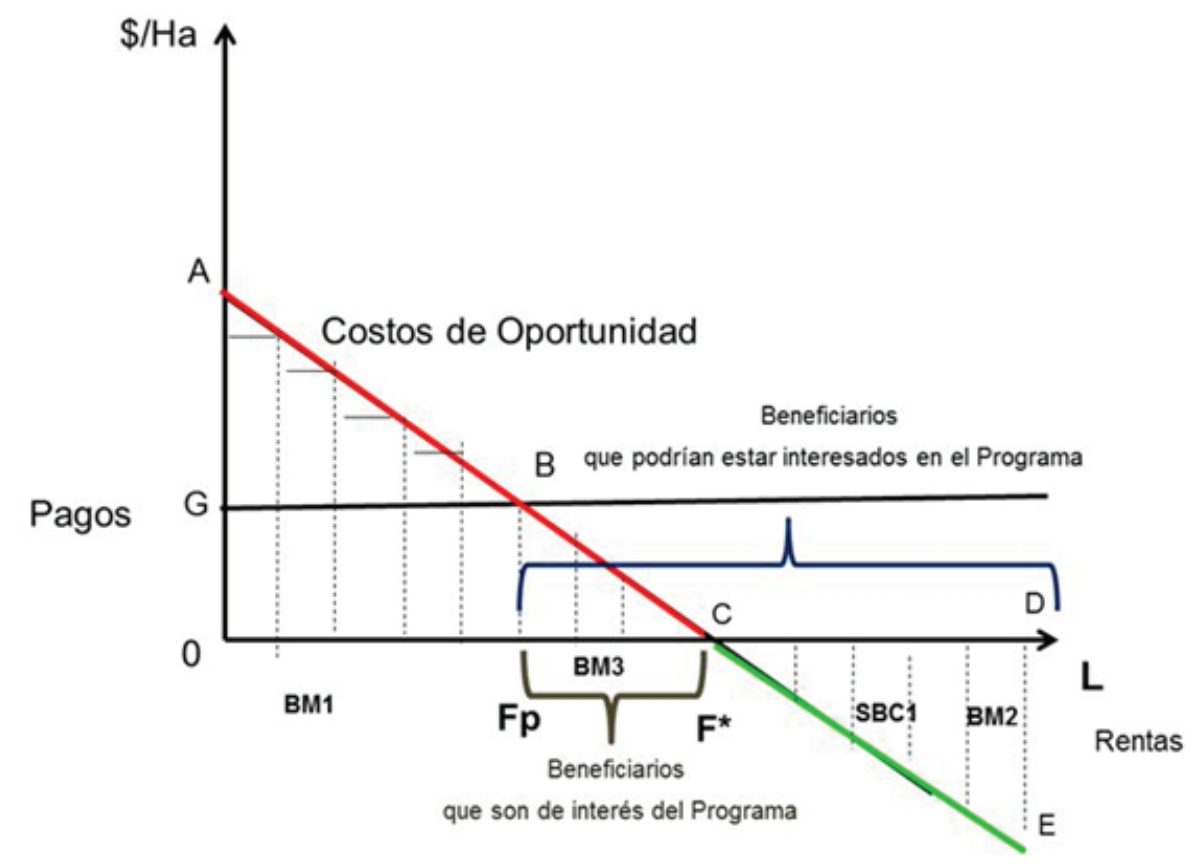

Fuente: Elaboración propia, adaptado de Robalino et al., 2008 
Los costos de oportunidad del uso del suelo forestal disminuyen conforme el predio se encuentra alejado del centro urbano (0), mismos que están reflejados en la línea de pendiente negativa $\mathrm{AE}$. Los predios que se encuentran distribuidos en la distancia 0L son de diferentes tipos de bosques, pero sólo se resaltan cuatro predios para efectos ilustrativos: los bosques mesófilos $\left(\mathrm{BM}_{1}, \mathrm{BM}_{2}\right.$ y $\left.\mathrm{BM}_{3}\right)$ y la selva baja caducifolia $\left(\mathrm{SBC}_{1}\right)$ ubicados a diferentes distancias del centro urbano y con diferentes costos de oportunidad. Si el regulador desconociera los verdaderos costos de oportunidad y los proveedores de servicios ambientales no los revelaran ex ante, mediante el establecimiento de un mecanismo de subastas el regulador podría disponer de la verdadera información sobre las ganancias a las que renunciarían los propietarios forestales por el uso alternativo que le darían al predio, y el gobierno podría a través de una subasta con discriminación de precios perfecta obtener todo el excedente de los productores y maximizar el valor de los beneficios ambientales con un presupuesto fijo. En este caso, las rentas creadas por la decisión de gobierno con un poder monopsónico serían mínimas (los triángulos pequeños dentro del triángulo mayor $\mathrm{ABC}$ ) y no habría espacio para que los buscadores de rentas realizaran actividades improductivas.

Si por diversas circunstancias (i.e. poca viabilidad política o administrativa de las subastas) el regulador decidiera fijar un precio constante, independientemente del tipo de bosque y del costo de oportunidad, se generarían las rentas de la magnitud del triángulo $\mathrm{CDE}$, mismo que los grupos de interés con un costo de oportunidad por debajo del pago fijo por hectárea estarían dispuestos a disputarse en beneficio propio. La búsqueda de rentas podría darse por el simple hecho de proveer de información al regulador sobre la importancia hidrológica de los bosques mesófilos $\mathrm{BM}_{2}$ o de la selva baja caducifolia $\left(\mathrm{SBC}_{1}\right)$ ubicados dentro de la distancia $\mathrm{F}^{*} \mathrm{~L}$, para que fueran incorporados en las áreas elegibles o en los criterios de prelación del programa. En este caso, el propietario del bosque $\mathrm{BM}_{2}$ (o la organización que los representa en la toma de decisiones) podría convencer al regulador (mediante evidencia científica y/o persuasión) de que ese tipo de vegetación o ecosistema resulta fundamental para la recarga de los acuíferos, objetivo último de la conservación de los bosques para la provisión de servicios ambientales hidrológicos. Los propietarios de los predios 
$\mathrm{BM}_{1}$ y $\mathrm{BM}_{2}$ podrían decidir no invertir recursos privados ni tiempo en la negociación, ya que la decisión de gobierno sería un bien público para ellos, además de que, en todo caso, el propietario $\mathrm{BM}_{2}$ tiene unos costos de oportunidad muy altos, que el pago constante $\mathrm{G}$ no alcanza a compensar. Adicionalmente, el propietario del bosque $\mathrm{BM}_{2}$ puede detectar que su predio se encuentra clasificado en las estadísticas oficiales y de acceso público de los institutos de investigación con una baja probabilidad de ser deforestado (por estar alejado del centro urbano, tener una pendiente del terreno muy empinada, ganancias negativas por actividad agrícola o ganadera, etc.), y no calificaría su solicitud de recibir los pagos (y las rentas) de seguirse únicamente este criterio de selección (pero sí podría ser seleccionado con una combinación de criterios secundarios y primarios). Por ello tiene todos los incentivos para buscar una parte de las rentas que se generaron por esta decisión de política pública. Bajo tal supuesto, el gobierno - como intermediario entre los intereses del último principal, es decir, la sociedad, y los proveedores de los servicios ambientales - sólo estaría interesado en atraer a los predios (indistintamente del tipo de bosque u otra característica de que se trate) que se encontraran en la distancia $\mathrm{FpF}^{*}$, ya que son aquellos propietarios que tienen un costo de oportunidad positivo pero menor o igual al pago fijo G. El último principal — la sociedad - no estaría interesada en compensar a los predios ubicados en $\mathrm{F}^{*} \mathrm{~L}$, ya que esos propietarios conservarían los bosques sin necesidad de algún pago.

Si se considerara que el gobierno ha elegido el pago de las compensaciones a partir de un monto fijo por hectárea y resolviera orientar sus decisiones de acción para el cumplimiento de los objetivos del PSAH a partir de indicadores de efectividad (i.e. porcentaje de cobertura forestal nacional incorporada al PSAH), los tomadores de decisiones elegirían la combinación de predios $\mathrm{BM} 3+\mathrm{SBC} 1+\mathrm{BM} 2$, ya que con su incorporación se cubrirían sus costos de oportunidad y se tendría el máximo de superficies cubiertas con el presupuesto disponible. La decisión arrojaría buenos resultados en términos de efectividad, pero no de eficiencia y equidad. Este mecanismo de precios no generaría una asignación equitativa de recursos presupuestales hacia los proveedores de los SAH del mismo tipo de bosques, ya que en tanto MB2 y MB3 recibirían los mismos montos del pago por hectárea, MB1 no ingresaría al programa (y no obtendría pago alguno) 
porque su costo de oportunidad excedería el pago por conservación del suelo forestal. Sin embargo, entre los proveedores que podrían estar interesados en el programa ubicados en FpL este mecanismo si generaría una asignación equitativa entre los predios, puesto que el monto sería el mismo por hectárea para el mismo tipo de bosque.

Si el gobierno decidiera utilizar indicadores y criterios de eficiencia para orientar la asignación de un presupuesto fijo se tendrían que seguir los siguientes principios: 1) disminuir o eliminar las rentas derivadas de cualquier decisión concerniente en la creación de zonas de elegibilidad o mecanismos de precios, 2) pagar los predios que ofrecieran mayor valor de servicios ambientales hidrológicos y 3) elegir los predios con costos de oportunidad mayores que cero. Esto podría lograrse si se eligiera un mecanismo que extrajera totalmente el excedente del productor, a partir de una discriminación perfecta de precios, o redujera las rentas creadas por pagos fijos al focalizar los pagos a los predios ubicados en $\mathrm{FpF}^{*}$. Al utilizar un indicador de eficiencia, ciertamente no se garantiza la equidad (ya que no garantiza que el mismo tipo de bosque o ecosistema recibiría un monto igual por hectárea al utilizar el costo de oportunidad de cambiar el uso de suelo, indistintamente del tipo de bosque de que se trate) ni la efectividad, pues no se buscaría incorporar predios que tuvieran costos de oportunidad negativos. No obstante, al guiar las acciones para el cumplimiento de los objetivos del PSAH a partir de un indicador de eficiencia, se alcanzaría el objetivo último del PSAH de maximizar el valor de los servicios ambientales hidrológicos que proveen los bosques con un presupuesto limitado.

La preferencia del regulador por utilizar criterios de efectividad en la asignación del presupuesto fijo queda de manifiesto en la Evaluación Específica de Desempeño 2009-2010 que la Coneval le hizo al PSAH de la Conafor y en los criterios de prelación utilizados para la calificación de solicitudes en las Reglas de Operación 2012. En el primer caso, se resalta que "el Coneval reconoce el esfuerzo que han realizado los responsables del programa en la elaboración de indicadores. Sin embargo, también se recomienda continuar trabajando para mejorar el conjunto de indicadores que reflejen de manera integral y fiel los resultados y avances del programa (Coneval, 2011, pag. 20)". 
Según el Coneval, entre los indicadores susceptibles de mejora se encuentran los de resultados, ya que si bien están correctamente definidos, éstos no alcanzan a medir si el fin último del programa se está cumpliendo en virtud de la carencia de indicadores de impacto del programa. Los tres indicadores de resultados del PSAH definidos por la Conafor, son: 1) porcentaje de superficie forestal nacional que ha sido conservada y protegida a través de esquemas de PSAH, 2) superficie incorporada anualmente al PSAH y 3) porcentaje de áreas prioritarias conservadas. Salvo el indicador de porcentaje de áreas prioritarias conservadas que lleva un avance del $99 \%$, los otros dos indicadores de resultados del PSAH son acumulables, y si bien existe un límite superior para el denominador del indicador de porcentaje de superficie forestal nacional que ha sido conservada y protegida a través de PSAH, a saber, 27 millones 400 mil hectáreas, hasta 2009 sólo había sido incorporada $1.3 \%$ del total de la superficie total forestal del país a un ritmo promedio de 213 mil hectáreas anuales de 2003 a 2009.

Ante la falta de definición de indicadores (y evaluaciones de impacto) la Conafor está midiendo el avance en el cumplimiento de los objetivos del PSAH con base en indicadores de resultados en los que el grado relativo de éxito se mide de acuerdo con el número de hectáreas de bosques y selvas que son incorporadas anualmente al programa, es decir, se privilegia la efectividad (lograr alcanzar una meta ya establecida, por ejemplo, cubrir la mayor parte del territorio forestal a nivel nacional con el programa) sobre la eficiencia (por ejemplo, incorporar bosques y selvas con costos de oportunidad positivos, con precios diferenciados que eliminen o disminuyan la creación de rentas y predios con un alto valor de servicios ambientales hidrológicos). Al seguir estos criterios se prioriza la cantidad de hectáreas incorporadas y la calidad de los servicios ambientales que éstas proveen queda en un segundo o tercer plano.

Con esta decisión del regulador no sólo existe un amplio espacio para la búsqueda de rentas (área CDE en la fugura 2), sino que también existen un desperdicio de los recursos aportados (a través de la Ley Federal de Derechos) por el último principal (la sociedad) sub-representado en el Comité técnico del PSAH por el problema clásico de acción colectiva ya que se podrían incorporar al programa predios que podrían conservarse sin necesidad de un pago de compensación (ubicados en la distancia $\mathrm{F}^{*} \mathrm{~L}$ en la figura 2) y que pudieran tener un valor de servicios ambientales de dudosa calidad. 
Con el propósito de aportar evidencia científica a la Conafor para que en el PSAH se incluyeran tanto los criterios de efectividad como también los de eficiencia económica, el INE realizó a finales de 2011 escenarios en los cuales se buscaba mantener tanto el ritmo promedio de incorporación de hectáreas de bosques, y selvas al PSAH, con una restricción presupuestal y también hubiera discriminación de precios entre los distintos ecosistemas según el costo de oportunidad de que se cambiara el uso del suelo forestal a otra actividad económica alternativa. En este sentido, se generaron dos escenarios, cuyos supuestos principales fueron: 1) presupuesto fijo anual de 134 millones de pesos (70\% del presupuesto más bajo ejercido por la Conafor para PSAH de 2003 a 2009 que fue de 199 millones de pesos); 2) 300 mil nuevas hectáreas de bosques y selvas incorporadas al PSAH (para continuar con el ritmo promedio anual de los últimos años); 3) elasticidad precio de la oferta de bosques unitaria (i.e. cada $10 \%$ de incremento en los pesos pagados por hectárea aumenta la oferta de superficie de bosques de cada tipo de ecosistema en 10\%); si la elasticidad observada fuera menor, las superficies cambiarían menos que lo proyectado, logrando menores aunque significativos efectos en la deforestación verdaderamente evitada. La Tabla 1 refleja los principales resultados de las estimaciones. En la opción (a) se calculó que el monto de hectáreas incorporadas sería de 304 mil hectáreas con un presupuesto de \$135 millones de pesos. Para la opción (b) estimamos que la superficie incorporada bajaría a 290 mil hectáreas, cubiertas con un presupuesto de $\$ 133$ millones de pesos.

Tabla 1. Escenarios de eficiencia y efectividad en el PSAH

\begin{tabular}{|c|c|c|c|c|}
\hline $\begin{array}{c}\text { Tipo de } \\
\text { ecosistema }\end{array}$ & $\begin{array}{l}\text { Riesgo (presión } \\
\text { económica) a la } \\
\text { Deforestación }\end{array}$ & $\begin{array}{c}\text { RdOp } \\
2011\end{array}$ & $\begin{array}{c}\text { RdOp } 2012 \\
\text { propuesta } \\
\text { INE-a/ }\end{array}$ & $\begin{array}{c}\text { RdOp } 2012 \\
\text { propuesta } \\
\text { INE-b/ }\end{array}$ \\
\hline \multirow{2}{*}{$\begin{array}{l}\text { Bosque Coníferas, } \\
\text { Bosque Encino y } \\
\text { Selva Subcaducifolia }\end{array}$} & Alto y Muy Alto: & \multirow{2}{*}{$\$ 382$} & $\$ 633$ & $\$ 688$ \\
\hline & $\begin{array}{l}\text { Medio, Bajo y } \\
\text { Muy Bajo }\end{array}$ & & $\$ 325$ & $\$ 287$ \\
\hline $\begin{array}{l}\text { Selva Alta Pereni- } \\
\text { folia }\end{array}$ & Alto y Muy Alto & $\$ 382$ & $\$ 633$ & $\$ 688$ \\
\hline
\end{tabular}

Fuente: Muñoz-Piña, Carlos, et. al., 2011 b/, “Análisis y recomendaciones de reforma a las Reglas de Operación de Proárbol-PSAH para el ejercicio fiscal 2012", Documento interno de trabajo del Instituto Nacional de Ecología. 
Tabla 2. Comparativo de criterios de prelación seleccionados ejercicio fiscal 2011 y 2012 del PSAH

\begin{tabular}{|c|c|c|}
\hline \multicolumn{1}{|c|}{ Criterios } & $\mathbf{2 0 1 1}$ & $\mathbf{2 0 1 2}$ \\
\hline Solicitudes que estén dentro de los municipios de la estrategia & 5 & N/A \\
\hline $\begin{array}{l}\text { EI solicitante manifiesta expresa y formalmente mediante escrito } \\
\text { libre entregado al momento de presentar su solicitud de apoyo, } \\
\text { que está dispuesto a asumir la obligación de conservar una } \\
\text { superficie adicional a la solicitada que cumpla con los criterios de } \\
\text { ejecución aplicables a este concepto de apoyo, así como las demás } \\
\text { disposiciones y obligaciones previstas en estas reglas de operación. } \\
\text { Este criterio aplicará para los predios en donde el tipo de ecosistema } \\
\text { predominante sea selva, de acuerdo a la cartografía de Uso de Suelo } \\
\text { y Vegetación serie IV de INEGI. }\end{array}$ & \\
\hline $\begin{array}{l}\text { La superficie adicional que compromete a conservar, y que cumple } \\
\text { con los criterios de ejecución, es 200\% mayor a la superficie solicitada }\end{array}$ & N/A & 3 \\
\hline $\begin{array}{l}\text { La superficie adicional que compromete a conservar, y que cumple } \\
\text { con los criterios de ejecución, es 100\% mayor a la superficie solicitada }\end{array}$ & N/A & 2 \\
\hline $\begin{array}{l}\text { La superficie adicional que compromete a conservar, y que cumple } \\
\text { con los criterios de ejecución, es 50\% mayor a la superficie solicitada }\end{array}$ & N/A & 1 \\
\hline
\end{tabular}

Fuente: Elaboración propia con información de las Reglas de Operación 2011 y 2012 del Proárbol-PSAH.

Al revisar y comparar las Reglas de Operación del Proárbol-PSAH se puede observar que la Conafor (apoyado en el Comité técnico consultivo $^{12}$ ) no sólo no incluyó la discriminación de precios para los ecosistemas faltantes (Bosque Coníferas, Bosque Encino y Selva Subcaducifolia y Selva Perennifolia) según el costo de oportunidad sino que también reafirmó su propósito de incorporar hectáreas adicionales al PSAH para cumplir

\footnotetext{
${ }^{12}$ Esto podría interpretarse como un incumplimiento parcial del artículo 27 de las Reglas de Operación del Proárbol 2011, en el que se señala que "con la finalidad de mejorar la eficiencia, eficacia y transparencia en la asignación y ejercicio de los apoyos, la CONAFOR con la participación que en su caso corresponda de las dependencias federales, estatales y de la sociedad en general, integrará un comité técnico nacional y un comité técnico estatal en cada una de las entidades federativas y del Distrito Federal" ya que en los criterios de selección de las solicitudes está teniendo un mayor peso la eficacia que la eficiencia en la asignación de los recursos públicos.
} 
con sus metas fijadas en el sexenio medidas a través de sus indicadores de resultados en los que el éxito se refleja con mayor cobertura del programa de la superficie forestal a nivel nacional poniéndole un menor peso a la calidad de los servicios ambientales que proveen las hectáreas apoyadas. Lo anterior es claramente visible en la Tabla 2 en la que puede observarse que a diferencia de 2011, en 2012 se añade el criterio de prelación en el que se da más puntos a quien incorpora más superficie forestal que la que se incluye en la solicitud de apoyo y que sería objeto de compensación. La hipótesis que subyace detrás de esta decisión es que la Conafor intuye que se lograría una mayor cobertura del programa con el mismo presupuesto fijo anual, si bien esto también podría generar el incentivo perverso de atraer bosques y selvas con costos de oportunidad negativos que se hubieran conservado de todas formas, es decir, sin necesidad de algún apoyo gubernamental. Luego entonces la Conafor estaría siendo efectiva en alcanzar sus objetivos administrativos pero como agente de la sociedad (último principal) estaría siendo ineficiente en el uso de los recursos. Los buscadores de rentas habrían obtenido ganancias importantes (si todos los predios inscritos estuvieran ubicados en $\mathrm{F}^{*} \mathrm{~L}$ sería de la cuantía del área CDE de la Gráfica 2) desviando recursos privados que pudieren utilizarse en actividades productivas a no productivas. El problema de acción colectiva de los usuarios de los servicios ambientales sólo refuerza este uso de recursos de forma ineficiente, cuestión que podría solucionarse si no existiera información asimétrica (provisión de evidencia científica) entre el regulador, los proveedores y los usuarios de servicios ambientales.

Los hallazgos encontrados en los apartados anteriores encuentran su fundamento teórico en los trabajos seminales de Becker (1983), North (1995) y Martimort y Semenov (2008). Becker (Op. Cit.) señala que la competencia entre grupos de interés por ganar influencia determina el equilibrio en el mercado de los impuestos, subsidios y otros favores políticos; North (Op. Cit.) a su vez señala que los individuos que buscan maximizar la riqueza hallarán con frecuencia que vale la pena cooperar con otros jugadores cuando el juego es repetido, cuando poseen información completa sobre los actos (o preferencias) de los otros jugadores y cuando el número de jugadores es pequeño. El modelo de Martimort y Semenov (Op. Cit.) es sumamente útil para analizar la organización e influencia de 
los grupos de interés en un modelo informacional de cabildeo sobre un regulador que tiene a su vez sus propias preferencias.

Finalmente, estos resultados del análisis son también un buen fundamento para consolidar una agenda de investigación empírica sobre la influencia de los grupos de interés en las decisiones de política ambiental y para realizar cálculos específicos del monto de las rentas creadas y distribuidas a individuos y grupos según su costo de oportunidad del uso del suelo y el precio pagado por la compensación. La evidencia analítica que se ha encontrado con respaldo en la literatura es que dado el diseño institucional vigente del PSAH, la creación y distribución de rentas y el uso de recursos reales en actividades improductivas por parte de los buscadores de rentas existe y se refuerza por los problemas de agente-principal, información asimétrica entre la Conafor, proveedores y usuarios de servicios ambientales y el problema de acción colectiva. Esta agenda de investigación empírica tiene un amplio potencial.

\section{REFLEXIONES DE POLÍTICAS PÚBLICAS}

El PSAH es un programa innovador dentro de las políticas ambientales de México que ha ido evolucionando con apoyo de los grupos organizados de proveedores de servicios ambientales y la provisión de evidencia científica para la toma de decisiones dentro de un contexto de apertura para la discusión de las modificaciones a sus Reglas de Operación. Sin embargo, su diseño institucional vigente del PSAH propicia la creación y distribución de rentas y el uso de recursos reales en actividades improductivas por parte de los buscadores de rentas. Esta situación se ve reforzada por los problemas de agente-principal, la información asimétrica entre la Conafor, proveedores y usuarios de servicios ambientales y el problema de acción colectiva a la que se enfrenta la sociedad en general ante la provisión de un bien público puro.

La Conafor requiere asumir el reto de tomar decisiones que disminuyan las rentas creadas a partir de los mecanismos de selección de predios y pagos que reduzcan el excedente de los proveedores de los servicios ambientales. De existir rentas fijas totales, diseñar un marco institucional 
que incentive la competencia -y no la colusión- y el libre acceso a los recursos públicos para que las rentas se disipen.

Es necesario alinear los incentivos del último principal -los votantes, electorado, contribuyentes, público en general, sociedad, usuarios de servicios ambientales- con los de los agentes reguladores para que éstos tomen decisiones en su representación. Para superar los problemas de acción colectiva se recomienda incluir a representantes los usuarios de los servicios ambientales en el comité técnico, ya que son el último principal de la cadena de toma de decisiones.

Las políticas ambientales estarán cercanas al óptimo de Pareto si los regulados y reguladores toman sus decisiones a partir de la evidencia científica existente y el marco institucional ofrece incentivos para que los segundos revelen sus preferencias.

Disminuir los incentivos al free-riding por parte de los usuarios de aguas nacionales al ser el servicio ambiental hidrológico que proveen los bosques un bien público local y regional convirtiendo el Comité técnico del PSAH en una arena de solución de conflictos de acceso común, esto es, disminuyendo las barreras de entrada de los usuarios de servicios ambientales, proveyendo de información oportuna del stock y los flujos del recurso, entre otros. Adicionalmente, se debería reformar la Ley Federal de Derechos para cobrarles las cuotas respectivas por el uso del agua a los usuarios exentos del pago.

Incentivar los mecanismos de pago por servicios ambientales locales para que exista un mayor contacto entre proveedores y usuarios, fomentando que los gobiernos federal, estatal y local actúen como intermediarios facilitadores del proceso y no como representantes únicos de los intereses del último principal.

Modificar los indicadores de resultados y de impacto del programa (i.e hectáreas incorporadas al Programa vs deforestación evitada), ya que los actuales no reflejan los fines que se persiguen en conformidad con las reglas de operación. 


\section{REFERENCIAS}

Aserca, 2003, “Acuerdo Nacional para el Campo: por el Desarrollo Rural Sustentable y la Soberanía y Seguridad Alimentaria”, disponible en http:// www.infoaserca.gob.mx/claridades/revistas/117/ca117.pdf, pags. 3-30.

Becker, Gary. 1983. "A theory competition among interest groups for political influence", The Quaterly Journal of Economics, 98 (3): 371-400.

Brubaker, Earl. 1997. "The Tragedy of the Public Budgetary Commons", The Independent Review, 1(3): 353 - 370.

Centro de Estudios para el Desarrollo Rural Sustentable y la Soberanía Alimentaria, 2006. "El Programa de Pago por Servicios Ambientales", disponible en http://www.cedrssa.gob.mx/?doc $=684$, pags. 7

Consejo Nacional de Evaluación, 2011. "Informe de la Evaluación Específica de Desempeño 2009-2010", disponible en http://www.coneval.gob. $\mathrm{mx} / \mathrm{cmsconeval} / \mathrm{rw} / \mathrm{pages} /$ evaluacion/evaluaciones/especificas/SEMARNAT.es.do, pags. 21

Flowers, Marilyn. 1987. "Rent Seeking and Rent Dissipation", Cato Journal, 7(2): 431-440

Guerrero Amparán, Juan Pablo y Mariana López Ortega, 2000. "Manual sobre el marco jurídico del presupuesto público federal", Centro de Investigación y Docencia Económica, disponible en http://www.derechoasaber. org.mx/documentos/pdf0063.pdf, pags. 61

Ley de aguas nacionales

Ley de desarrollo forestal sustentable

Ley federal de derechos

Ley federal de presupuesto y responsabilidad hacendaria

Lineamientos generales para la evaluación de los programas federales de la administración pública federal 
Martimort, D. y A. Semenov. 2008. "The informational effects of competition and collusion in legislative politics", Journal of Public Economics, 92(7): 1541-1563.

Muñoz-Piña, Carlos, et al., 2007. "Paying for hydrological services of Mexico's forests: Analysis, negotiations and results", en Ecological Economics, pags. 12

Muñoz-Piña, Carlos, et al., 2011 a/. "Retos de la focalización del programa de pago por los servicios ambientales en México", en Revista Española de Estudios Agrosociales y Pesqueros, No. 228, pags. 87-113

Muñoz-Piña, Carlos, et. al., 2011 b/. "Análisis y recomendaciones de reforma a las Reglas de Operación de Proárbol-PSAH para el ejercicio fiscal 2012", Documento interno de trabajo del Instituto Nacional de Ecología, México.

North, Douglas, 1995. Instituciones, cambio institucional y desempeño económico, México, Fondo de Cultura Económica, pags. 188

Poteete, Amy y Elinor, Ostrom, 2002. "An institutional approach to the study of forest resources", International Forestry Resources and Institutions (FPRI), disponible en http://www.indiana.edu/ workshop/papers/ W01I-8.pdf, pags. 32

Presidencia de la República de México, 2003. “Acuerdo Nacional para el Campo: Por el Desarrollo de la Sociedad Rural y la Soberanía y Seguridad Alimentarias", disponible en: http://fox.presidencia.gob.mx/docs/acuerdo_para_el_campo-280403.pdf, pags. 48.

Presidencia de la República de México, 2003. "Resultados de la Consulta Ciudadana para el Plan Nacional de Desarrollo 2007, 2012”, disponible en http://pnd.presidencia.gob.mx/pdf/Resultados_de_la_Consulta_Ciudadana_para_el_PND.pdf, pags. 3 . 
Red MOCAF A.C., 2009. "Propuesta de Programa Especial Concurrente 2010 del Consejo Mexicano para el Desarrollo Rural Sustentable", en Revista Electrónica Letra Verde, No. 9, disponible en http://mocaf.org.mx/ documentos-descarga/LetraVerde_9.pdf

Reglas de Operación de Proárbol, 2011.

Rivero, Edgar, 2008. "La división de Poderes en el proceso de negociación del presupuesto público federal en un gobierno democrático incipiente". Revista de Economía, Facultad de Economía de la Universidad, Autónoma de Yucatán XXIV(I), Nums. 68 y 69:23-50.

Robalino, J., et al., 2008. "Deforestation impacts of environmental services payments: Costa Rica's PSA Program 2000-2005”, Efd Resources for the Future, Working Paper Series Efd DP 08-24

Tollison, Robert, 1982. "Rent seeking: a survey”, Kylos, Vol. 35, pags. 575-602

Tullock, Gordon. 2003. "The origin of rent-seeking concept”, in International Journal of Business and Economics, Vol 2, No. 1, pags. 1-8.

Ugalde, L. C. 2002. Rendición de cuentas y democracia: el caso de México, Ediciones del Instituto Federal Electoral, México. 